\title{
PEDOGÊNESE EM UMA VERTENTE DO PLANALTO DE DIAMANTINA-MG: MORFOLOGIA DOS SOLOS E ANÁLISES QUÍMICAS DO COMPLEXO SORTIVO COMO INDICADORES DOS PROCESSOS PEDOGENÉTICOS
}

\author{
José Alves Ferreira Neto ${ }^{(a)}$, Bruna Fernandes Soares ${ }^{(b)}$ e Guilherme Taitson Bueno ${ }^{(c)}$, Nádia \\ Regina do Nascimento ${ }^{(\mathrm{d})}$
}

(a) Professor Ms.dos cursos de Engenharia de Minas e Civil da Universidade Presidente Antonio Carlos - UNIPAC Lafaiete, jose.neto@unipaclafaiete.edu.br

(b) Doutoranda - bolsista FAPEMIG no programa de Pós-Graduação em Geografia - Tratamento da Informação Espacial, Pontifícia Universidade Católica de Minas Gerais, brunafernandesgeo@yahoo.com.br

(c) Professor Dr. do Instituto de Estudos Socioambientais (IESA), Universidade Federal de Goiás (UFG) . gtaitsonbueno@gmail.com.

(d) Professora Dra - IGCE/UNESP - Rio Claro. nascimer@rc.unesp.br

\section{EIXO 11: SOLOS E PAISAGENS}

\section{Resumo}

O propósito deste trabalho é discutir a pedogênese de uma vertente representativa dos topos do Planalto de Diamantina - MG visando contribuir para o conhecimento dos solos dos platôs da Serra do Espinhaço Meridional, ainda escassos. Foram utilizados dados de morfologia e análises químicas (pH, CTC, Saturação por bases e MO) dos solos. Nove trincheiras foram abertas ao longo da vertente e 77 amostras de solos foram coletadas. As análises químicas do complexo sortivo foram realizadas no Laboratório de Análise de Solos da Universidade Federal de Viçosa. Os resultados indicam que: i) os solos na vertente são ácidos e apresentam baixa fertilidade, ii) a CTC está diretamente correlacionada à presença da $\mathrm{MO}$ e iii) o processo de laterização domina na alta/média vertente (TR1-TR6) enquanto que na baixa vertente verifica-se gleização e a podzolização em ambiente hidromórfico.

Palavras chave: Pedogênese. análise química. Planalto de Diamantina-MG

\section{Introdução}

A Serra do Espinhaço constitui uma das unidades geológicas e geomorfológicas mais importantes do Brasil. Sua relevância dentro do cenário geológico brasileiro é confirmada por inúmeros trabalhos científicos estimulados principalmente pela descoberta de depósitos diamantíferos no início do século XVIII. Existe, todavia, uma carência de estudos quando se trata dos solos existentes nos platôs do setor meridional da Serra do Espinhaço, mais especificamente no Planalto de Diamantina. Esse planalto se caracteriza por superfícies entre 1200 e 1450 metros de altitude, com ampla variedade de tipos de solos. Uma sequência de cobertura pedológica comum nessa área é aquela que parte dos topos planos com ambiente ortomórfico e solos lateríticos (Latossolos e Cambissolos) ou Neossolos, e termina em vales hidromórficos, com Espodossolos e solos orgânicos (MINAS GERAIS, 2004; SCHAEFER et al., 2002). 
Nessa topossequência clássica de solos no Planalto de Diamantina verifica-se, assim, a predominância do processo de laterização nos topos planos das vertentes e predominância do processo de hidromorfia na base das vertentes.

O processo pedogenético de laterização se caracteriza pela intensa lixiviação dos elementos alcalinos, alcalino terrosos e sílica livre do pedoambiente tropical de drenagem livre e $\mathrm{pH}$ moderadamente ácido, bem como uma consequente acumulação de óxidos de ferro e alumínio (TARDY, 1993). O hidromorfismo, por sua vez, refere-se ao processo de saturação permanente ou sazonal dos solos devido à estagnação da água, ocasionada pelas condições de má drenagem e oscilação do nível freático em resposta à variação das estações climáticas ao longo do ano (VIEZER, 1983). Pode ocorrer, portanto, nas áreas mais baixas do terreno ou em depressões localizadas (RESENDE et al., 2002; ROSOLEN, HERPIN e MELFI, 2007).

Schaefer et al. (2002) afirmam, ainda, que nessa mesma topossequência clássica de solos do Planalto de Diamantina pode-se verificar uma sequência gradativa do aumento de condições hidromórficas do topo à base das vertentes, onde os minerais de argila são destruídos em baixo pH e sofrem ferrólise no ambiente mal drenando de jusante. Ressalta-se, entretanto, que entre o pedoambiente bem drenado de solos lateríticos e o pedoambiente mal drenando dos solos hidromórficos há uma faixa de transição, em que a flutuação sazonal do nível freático propicia condições para a dissolução seletiva dos óxidos de Fe e para a instauração do processo de podzolização. Vieira (1988) afirma que este processo é consequente tanto da lixiviação dos cátions básicos, quanto do desenvolvimento de condições ácidas nos horizontes superficiais, as quais tendem a causar protonação e desestabilização dos minerais de argila. A podzolização é considerada pelo ISSS WORKING GROUP (1998) como um processo secundário, desenvolvido a partir de solos originalmente arenosos ou previamente empobrecidos em argila. A podzolização é desencadeada após o desenvolvimento da porosidade entre grãos de quartzo, o que permite a migração da matéria orgânica no perfil (FRITSCH et al., 1989; 2011).

Curi e Kampf (2012) acreditam que as propriedades do solo são fortemente influenciadas pelo pH, dessa forma, em solos ácidos a maioria dos minerais são mais solúveis que em soluções neutras ou levemente alcalinas. Sauer et al. (2007) afirmam, por exemplo, que os baixos teores de pH verificados nos ESPODOSSOLOS aumentam a capacidade de destruição dos minerais primários silicatos e argilominerais, conduzindo, portanto, à liberação de $\mathrm{Al}$, Fe e Si na solução dos solos, que poderão ser mobilizados e exportados.

A capacidade de troca catiônica (CTC) é um importante indicador para o estudo das propriedades dos solos, pois os baixos valores de CTC indicam capacidade reduzida de reter nutrientes, como $\mathrm{Ca}, \mathrm{Mg}$ e $\mathrm{K}$, os quais são perdidos por lixiviação. A CTC implica também na acidez e basicidade do solo, atuando 
também na purificação ou alteração das águas de percolação. As condições gerais de fertilidade do solo são identificadas através da saturação por bases (V), a qual é expressa em porcentagem de capacidade de troca de cátions obtida pela soma das bases trocáveis. Os solos eutróficos apresentam saturação por bases maior ou igual a 50\%, enquanto que solos distróficos apresentam este índice inferior a 50\% (RONQUIM, 2010).

De acordo com Dick et al. (2009), a matéria orgânica do solo (MOS) refere-se ao material orgânico morto do solo. A MOS altera as propriedades físicas e químicas do solo, servindo ainda como fonte de $\mathrm{C}$ orgânico e nutrientes para os microrganismos. A MOS contribui com cargas negativas para o solo, mas as condições do meio, principalmente $\mathrm{pH}$, influenciam na carga da MOS.

Diante do exposto verifica-se que as análises do complexo sortivo (CTC em pH 7, Saturação por bases e Matéria Orgânica), as quais indicam a fertilidade dos solos, e a mensuração do $\mathrm{pH}$ fornecem variáveis fundamentais para caracterizar a cobertura pedológica e estabelecer considerações acerca da gênese e evolução dos solos de uma determinada paisagem. Dessa forma, o propósito deste trabalho consiste em discutir os processos pedogenéticos em topossequência de uma vertente representativa do Planalto de Diamantina, localizada no Parque Estadual do Biribiri (PEB), utilizando características morfológicas e parâmetros de análises químicas (pH, CTC, Saturação por bases e Matéria Orgânica) dos solos como indicativos de pedogênese.

\section{Caracterização da Área de Estudo}

A vertente investigada localiza-se na superfície cimeira do Planalto de Diamantina (18 $11^{\circ}$ '48.2" S / $43^{\circ} 35^{\prime} 52.5^{\prime \prime} \mathrm{W}$ (montante) e 18 $11^{\prime} 57.6^{\prime \prime} \mathrm{S} / 43^{\circ} 35^{\prime} 54.1^{\prime \prime} \mathrm{W}$ (jusante)), a $1.427 \mathrm{~m}$ de altitude (topo), na porção meridional do Parque Estadual do Biribiri, onde se instalam as cabeceiras de drenagem do Córrego da Roda, em Diamantina - MG (Figura 1). 


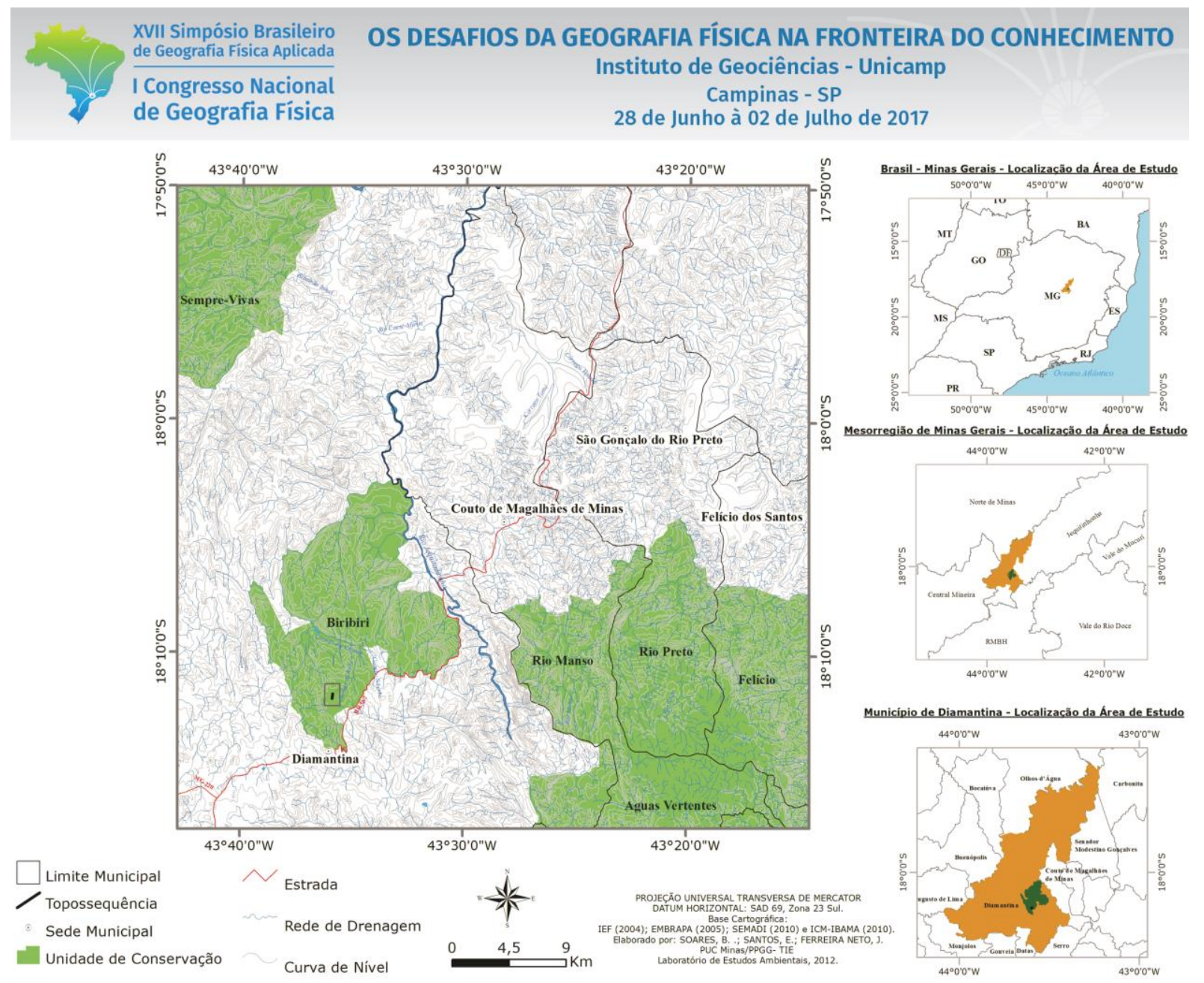

Figura 1 - Mapa de localização do Parque Estadual do Biribiri, Diamantina - MG.

A geologia do Parque Estadual do Biribiri apresenta estrutura em estratificação plano-paralela, com suaves ondulações, predominando rochas quartzíticas (REIS NETO, 2004). Os estudos de topossequência dos solos realizados por Ferreira Neto (2012) e Soares (2013) na vertente aqui estudada indicaram que o substrato geológico é heterogêneo, predominando fácies filíticas na parte de montante e na média vertente, e fácies quartzíticas mais puras na baixa vertente, onde há, inclusive, um afloramento dessa rocha.

De acordo com Minas Gerais (2004), nas superfícies de aplainamento entre 1250 e 1400 metros de altitude, onde o relevo varia de plano a suave ondulado, ocorre o Neossolo Quartzarênico Hidromórfico típico, todavia, Soares (2013) caracterizou os solos da vertente como: CAMBISSOLO AMARELO, CAMBISSOLO HÁPLICO e o ESPODOSSOLO FERRIHUMILÚVICO.

O clima do Parque Estadual do Biribiri é caracterizado como tropical, tendo duas estações bem definidas, sendo uma estação muito chuvosa e outra seca, com precipitação média anual de 1.404,7 mm e temperaturas cujas médias anuais estão em torno de 18 a $19^{\circ} \mathrm{C}$ (FRAGA, 2004). 
3. Procedimentos Metodológicos

28 de Junho à 02 de Julho de 2017

O estudo do solo foi feito com base na Análise Estrutural da Cobertura Pedológica (BOULET, 1988). Assim, na vertente foram realizadas 29 tradagens, com o objetivo de identificar as diferenças laterais e verticais dos solos. Após estas sondagens abriram-se 9 trincheiras (TR), onde foram descritas as características morfológicas dos horizontes dos solos, segundo os procedimentos de Santos et al. (2005), e coletadas as amostras representativas de cada horizonte dos solos, que após serem devidamente embaladas e identificadas foram enviadas para análises em laboratório. Para a análise química do complexo sortivo foram, portanto, selecionadas 77 amostras, as quais foram enviadas para o Laboratório de Análise de Solos da Universidade Federal de Viçosa (UFV).

Assim, as análises do complexo sortivo, que incluem a determinação dos cátions trocáveis $\left(\mathrm{Ca}^{2+}, \mathrm{Mg}^{2+}\right.$, $\left.\mathrm{K}^{+}, \mathrm{Na}^{+}, \mathrm{H}^{+}, \mathrm{Al}^{3+} \mathrm{e}^{3+}\right), \mathrm{pH}\left(\mathrm{H}_{2} \mathrm{O}\right)$, Carbono Orgânico e Nitrogênio Total, foram realizadas com o objetivo de determinar as condições que regulam os processos pedológicos do sítio de estudo, conforme Michelon (2011) apontou.

No Laboratório de Análise de Solos da Universidade Federal de Viçosa (UFV) as determinações de pH

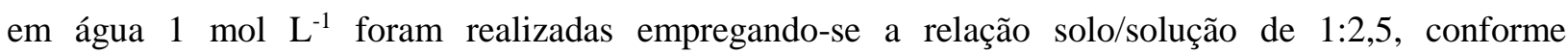
procedimento analítico descrito por Defelipo e Ribeiro (1997).

Os íons $\mathrm{Ca}^{2+} \mathrm{e} \mathrm{Mg}^{2+}$ foram extraídos com $\mathrm{KCl} 1 \mathrm{~mol} \mathrm{~L}^{-1}$ e determinados com EDTA 0,025 mol L-1; o Al ${ }^{3+}$

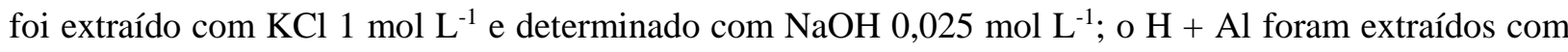
acetato de cálcio $0,5 \mathrm{~mol} \mathrm{~L}^{-1}$ a pH 7,0 e determinados com $\mathrm{NaOH} 0,025 \mathrm{~mol} \mathrm{~L}^{-1}$; os íons $\mathrm{K}^{+}$e $\mathrm{Na}^{+}$foram extraídos com extrator Mehlich-1 e determinados no fotômetro de chama (EMBRAPA, 1999). Por fim, o carbono orgânico foi determinado pelo método Walkley-Black (WALKEY; BLACK, 1934).

\section{4. $\quad$ Resultados e Discussões}

A vertente estudada (Figura 2) possui $310 \mathrm{~m}$ de comprimento, inicia-se em um topo aplanado, situado a $1427 \mathrm{~m}$ de altitude e termina em um vale hidromórfico aberto, de fundo plano, situado a $1414 \mathrm{~m}$ de altitude. Esta vertente pode ser divida em três compartimentos: i) Alta vertente (TR1, TR2, TR3): porção superior da vertente, cuja litologia predominante é o filito, com intercalações de filito hematítico, apresenta condições de drenagem livre, forma retilínea a levemente convexa, declividade próxima de $1^{\circ} \mathrm{e}$ predomínio dos horizontes Laterítico; ii) Média vertente (TR4, TR8, TR5): situada no terço médio da vertente, tem também o filito como rocha predominante, a drenagem é parcialmente livre, a forma é levemente convexa e a declividade próxima de $3^{\circ}$. Os horizontes saprolíticos são caracterizados por serem Lessivados (empobrecidos em argila e silte) e os mais superficiais são Lateríticos friáveis; iii) 
XVII Simpósio Brasileiro

de Geografia Física Aplicada

I Congresso Nacional

de Geografia Física
OS DESAFIOS DA GEOGRAFIA FÍSICA NA FRONTEIRA DO CONHECIMENTO

Instituto de Geociências - Unicamp

Campinas - SP

28 de Junho à 02 de Julho de 2017

Baixa vertente (TR6, TR9, TR7): porção inferior da vertente, que termina no fundo de vale chato, sob condições de hidromorfia. Na porção montante deste compartimento predominam as rochas do tipo filito, a forma é convexa, a declividade é de $4^{\circ}$ e horizontes Lessivado são predominantes. Na porção jusante, contudo, a rocha matriz é o quartzito, a forma é côncava e o declive também é próximo de $4^{\circ}$, diminuindo progressivamente até o fundo plano do vale, onde predominam os horizontes Orgânico.

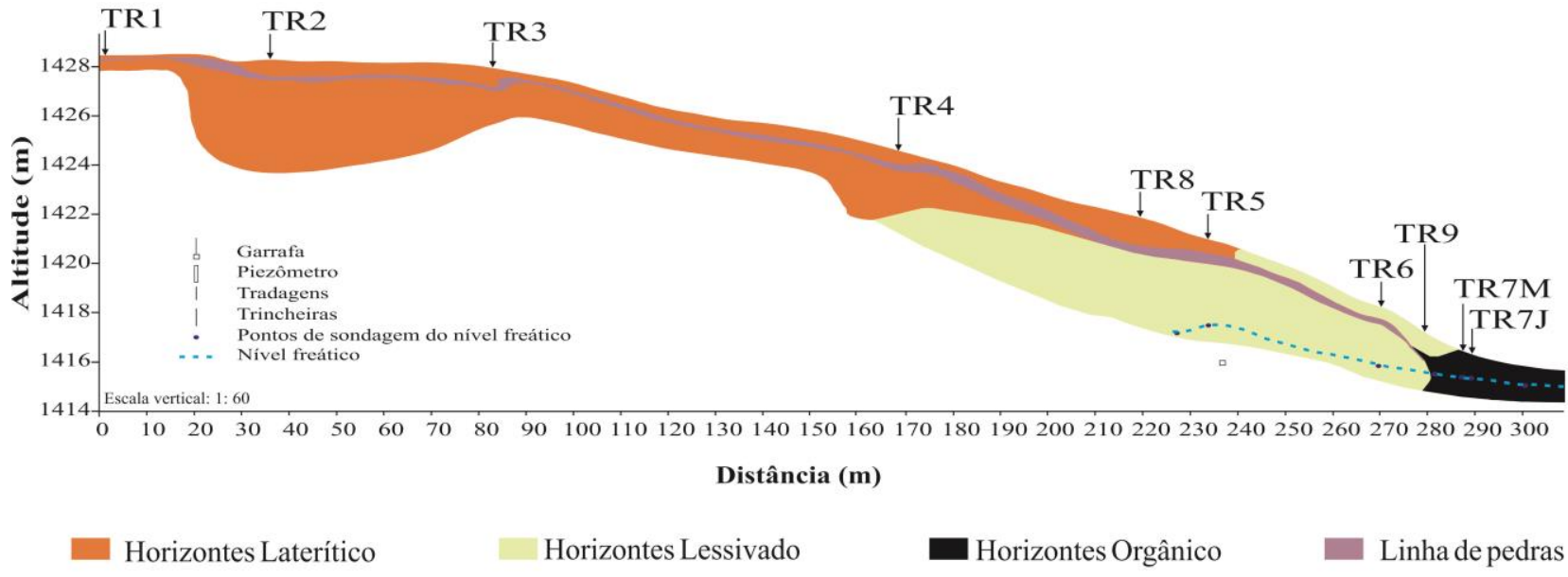

Figura 2: Localização das trincheiras ao longo da vertente investigada - Parque Estadual do Biribiri/ Diamantina MG. Adaptado de SOARES, 2013.

Os valores de $\mathrm{pH}$ dos solos da vertente indicam que dois tipos de distribuição vertical podem ser observados, isto é, um para os perfis de TR1 a TR6 e outro para os dois perfis da TR7 (TR7M e TR7J). Assim, para os perfis de TR1 a TR6 observa-se que ocorre diminuição do pH da base dos perfis rumo ao topo, com valores mínimos encontrados no horizonte superficial A, e tendência, embora não muito evidente, da diminuição do pH de montante para jusante. Para os perfis da TR7, observa-se que os valores mais baixos de $\mathrm{pH}$ foram encontrados a aproximadamente $20 \mathrm{~cm}$ de profundidade, correspondendo ao horizonte Bh1. No perfil TR7J a variação de pH, em $10 \mathrm{~cm}$, do horizonte E para o horizonte Bh1 é de uma unidade $(5,4$ a 4,4). Ao contrário dos perfis de montante da vertente, o pH diminui com a profundidade, à medida que se aproxima do horizonte $\mathrm{Bh} 2$.

$\mathrm{Na}$ alta vertente (TR1, TR2, TR3), média vertente (TR4, TR8, TR5) e na TR6 os valores encontrados para a CTC em pH 7 foram inferiores a $10 \mathrm{cmol}_{\mathrm{c}} / \mathrm{dm}^{3}$. Nesses compartimentos, observa-se uma tendência geral do aumento da CTC da base para o topo dos perfis, sendo os valores mais elevados encontrados nos horizontes superficiais. Verifica-se, também, uma tendência de diminuição da CTC de montante para 
jusante. Para os dois perfis de jusante (TR7M e TR7J), por sua vez, os maiores valores de CTC encontram-se nos horizontes superficiais e Bh2. Esse último apresenta, particularmente, valores bastante elevados, superiores a $21 \mathrm{cmol}_{\mathrm{d}} / \mathrm{dm}^{3}$ no perfil da TR7J.

A distribuição da matéria orgânica ao longo da vertente apresenta configuração bastante semelhante àquela apresentada pela CTC. Isso sugere que a capacidade de troca catiônica destes materiais se deve, essencialmente, à presença da matéria orgânica, sendo pouco representativo o papel dos argilo-minerais nos horizontes Laterítico e Lessivado. Todavia, nos horizontes Orgânico parece haver uma participação significativa dos argilo-minerais, principalmente nos horizontes mais profundos, pois neles os teores de matéria orgânica são muito baixos. No gráfico da figura 3 verifica-se que os materiais se distribuem segundo duas linhas de tendência: i) os materiais mais orgânicos, cujos pontos se distribuem em torno da linha contínua correspondem aos horizontes de acumulação orgânica subsuperficial do segmento de jusante (horizontes Orgânico), isto é, aos materiais da parte intermediária e basal dos perfis da TR7. Estes horizontes possuem uma maior concentração de argila, se comparado aos horizontes Laterítico e Lessivado, assim, os argilominerais presentes neste pedoambiente contribuem para aumentar os índices de CTC, mesmo que o teor de matéria orgânica neles não seja muito elevado; ii) os horizontes Laterítico mais orgânicos cujos pontos se distribuem em torno da linha tracejada correspondem aos horizontes de acumulação orgânica superficial dos perfis TR1 a TR6.

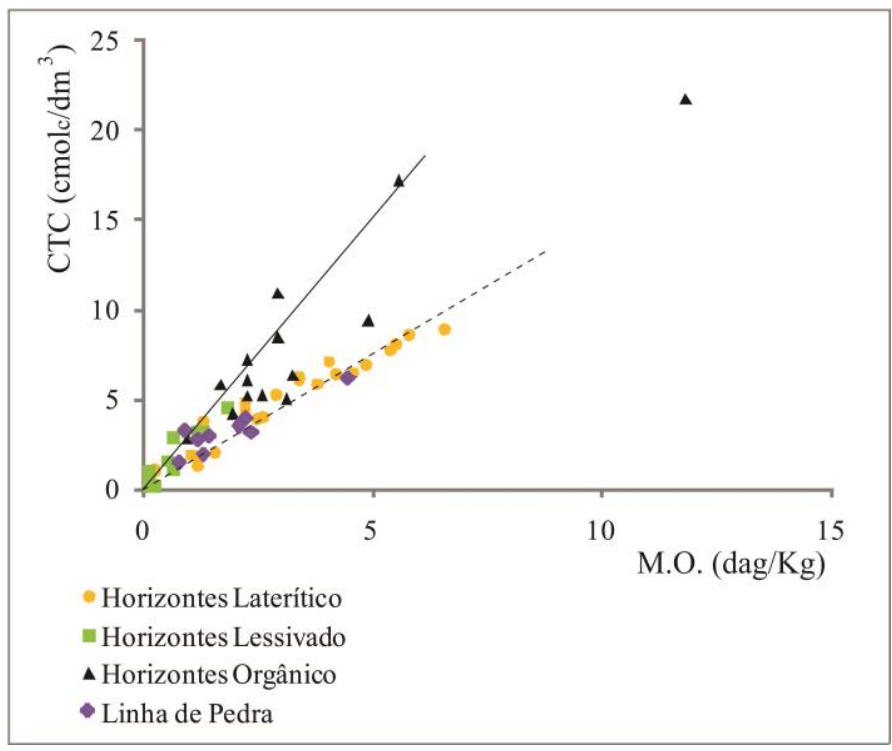

Figura 3: Gráfico de correlação entre a matéria orgânica e a CTC (pH 7) dos solos analisados em topossequência. 
Os altos teores de matéria orgânica encontrados na baixa vertente e o consequente aumento da CTC devem-se, possivelmente, à hidromorfia permanente que prevalece nesse pedoambiente, a qual cria condições para a instalação de um ambiente anaeróbico, que combinado com as baixas temperaturas devido à altitude, resulta em baixas taxas de decomposição e acumulação da MO.

A análise de Saturação por bases (V), por sua vez, indicou que todos os horizontes analisados são distróficos. Neste caso, os horizontes da parte superior da vertente e os horizontes da base da vertente (TR7) apresentam configuração parecida, ou seja, os horizontes superficiais têm maior saturação por bases se comparados aos horizontes do saprolito (valores são inferiores que $2 \%$ ). Na baixa vertente o valor de V decai nesses horizontes Orgânico superficiais. Na base dos perfis, nos materiais saprolíticos, a saturação por bases volta a aumentar, certamente devido ao menor grau de lixiviação desses horizontes menos alterados. O valor mais elevado de V (acima de 16\%) foi encontrado na base do saprolito (horizonte C) da TR1. Esses resultados mostram que o complexo sortivo é dominado fundamentalmente por $\mathrm{H}$ e $\mathrm{Al}$, sendo os cátions básicos pouco representativos.

Diante do exposto, pode-se inferir que os teores mais elevados de argila na base de TR7 devem-se provavelmente ao processo de lessivagem que ocorre na média/baixa vertente, já que o quartzito é a rocha matriz dessa trincheira. A lessivagem é definida por Duchaufour (1970) como um processo em que as argilas e o ferro são transportados de forma particulada em ambiente ligeiramente ácido e biologicamente ativo. Esse processo pode ocorrer tanto no sentido vertical do perfil do solo (desde os horizontes de eluviação (A e E) para os horizontes de iluviação (B)), como também no sentido lateral, isto é, ao longo das vertentes. Assim, a instalação de fluxos hídricos laterais, em decorrência do aprofundamento do nível de base (VIDAL-TORRADO et al., 1999) e a flutuação sazonal do nível freático (BUENO, 2009) podem influenciar no processo de transporte de partículas finas, tanto nos horizontes superficiais quanto nos mais profundos do pedoambiente.

Acredita-se, dessa forma, que a lessivagem, provavelmente, permitiu o início do processo de podzolização na média/baixa vertente, possivelmente, combinada com o processo de ferrólise, conforme descreveram Schaefer et al (2002) na vertente por eles estudada nessa mesma superfície de aplanamento.

\section{Considerações Finais}

Os resultados dessa pesquisa indicam que solos da vertente estudada são ácidos e apresentam baixa fertilidade. A alta e média vertente (TR1-TR6) apresentam alteração pedogenética diferenciada da baixa vertente (TR7), pois nos perfis TR1 a TR6 verifica-se diminuição do $\mathrm{pH}$ da base dos perfis rumo ao topo e diminuição no sentido montante para jusante. A CTC desses solos apresenta valores baixos, os quais aumentam da base para o topo dos perfis e diminuem no sentido da montante para jusante. Na baixa 
vertente (TR7), todavia, o pH diminui com o aumento da profundidade, isto é, os horizontes saprolíticos são mais ácidos que os horizontes do solum e os maiores valores de CTC foram encontrados no horizonte

Bh2. Os resultados bem correlacionados da distribuição da matéria orgânica e CTC, por sua vez, sugerem que a capacidade de troca catiônica ao longo da vertente ocorre na presença da matéria orgânica.

Diante do exposto, pode-se inferir que os solos da vertente representativa do Planalto de Diamantina, elaborados a partir da degradação de filitos e quartzitos são em geral pobres em nutrientes, ácidos e localmente submetidos às condições hidromórficas. Assim, as áreas de hidromorfia sazonal (média/baixa vertente) estão associadas a solos empobrecidos em argila e extremamente pobres em nutrientes e, as áreas com hidromorfia permanente (baixa vertente) associam-se a solos mais orgânicos, com CTC mais elevada e maior teor de nutrientes, sobretudo em profundidade.

\section{Bibliografia}

BOULET, R. Análise Estrutural da cobertura pedológica e cartografia. In: CONGRESSO BRASILEIRO DE CIÊNCIAS DO SOLO, 21, 1988, Campinas. Anais do XXI Congresso Brasileiro de Ciências do Solo. Campinas: Sociedade Brasileira de Ciência do Solo, 1988. p. 79-90.

BUENO, G. T. Empobrecimento e podzolização de solos lateríticos da Bacia do Rio Negro e gênese dos podzóis na Alta Bacia Amazônica. 2009. 157f. Tese (Doutorado) - Universidade Estadual Paulista, Instituto de Geociências e Ciências Exatas, Rio Claro.

CURI,N.; KAMPF, N. Caracterização do solo. In: Ker, J. C. et al. Pedologia, fundamentos. Viçosa-MG : SBCS, 2012.

DEFELIPO, B. V.; RIBEIRO, A. C. Análise química do solo (metodologia). 2. ed. Viçosa: Ed. Universidade Federal de Viçosa, 1997. 26p. (Boletim de extensão 29).

DICK, D. P.; NOVOTNY, E. H.; DIECKNOW, J.; BAYER, C. Química e matéria orgânica do solo. In: Melo, V. F, ALLEONI, L. R. F. Química e mineralogia do solo, V.2. Viçosa-MG : SBCS, 2009, p. 1-67.

DUCHAUfOUR, P. Précis de Pédologie. 3.ed. Paris: Masson et Cie Éditeurs, 1970. 438p.

EMPRESA BRASILEIRA DE PESQUISA AGROPECUÁRIA (EMBRAPA). Manual de análises químicas de solos, plantas e fertilizantes. Brasília: Centro Nacional de Pesquisa de Solos, 1999. 370p.

FERREIRA NETO, J. A. Mineralogia e gênese dos solos de uma vertente do Planalto de Diamantina - MG Parque Estadual do Biribiri - Serra do Espinhaço - MG. (Dissertação de mestrado). PUC Minas. Programa de Pós Graduação em Geografia: Tratamento da Informação Espacial. Belo Horizonte, 2012. 
FRAGA, L. Caracterização hidrográfica, qualidade das águas e limnologia: 2004. In: Plano de Manejo do Parque Estadual do Biribiri, 2004.

FRITSCH, E.; BALAN, E.; NASCIMENTO, N. R. do; ALLARD, T.; BARDY, M.; BUENO, G.T.; DERENNE, S.; MELFI, A. J.; CALAS, G. Deciphering the weathering processes using environmental mineralogy and geochemistry: towards an integrated model of laterite and podzol genesis in the Upper Amazon Basin. Comptes Rendus Geoscience, v. 343, p. 188-198, 2011.

FRITSCH, E.; HERBILlON, A. J; JEANROY, E.; PILLON, P.; BARRES, O. Variations minéralogiques et structurales accompagnant le passage "sols rouges- sols jaunes" dans un bassin versant caractéristique de la zone de contact forèt-savage de l'Afrique occidentale(Booro-Borotou, Cotêd'Ivoire). Sci. Geol. Bull., v. 42, n. 2, p. 65-89, 1989.

ISSS WORKING GROUP RB. DECKERS, J. A.; NACHTERGAELE, F. O; SPAARGAREN, O. C (Eds). World reference base for soil resources: introduction., ISRIC - FAO - ISSS - Acco, 1998.

MICHELON, C. R. Evolução de sistemas de solos lateríticos e podzolizado: inferências sobre a forma atual da Vertente - Bacia do Alto Rio Preto - MG. 2011. 115 f. Tese (Doutorado) - Universidade Estadual Paulista, Instituto de Geociências e Ciências Exatas, Rio Claro.

MINAS GERAIS. Plano de Manejo do Parque Estadual do Biribiri. V.1: Curitiba (PR): Secretaria de Estado de Meio Ambiente e desenvolvimento Sustentável (SEMAD), Instituto Estadual de Florestas (IEF), 2004. 160p.

(Encarte 2).

REIS NETO, J. M. Planos de Manejo dos Parques Estaduais do Pico do Itambé, do Biribiri e do Rio Preto. In: Plano de Manejo do Parque Estadual do Biribiri, 2004.

RESENDE, M. et al. Pedologia: base para a distinção de ambientes. 4. ed. Viçosa - MG: NEPUT, 2002. 338 p.

RONQUIM, C. C. Conceitos de fertilidade do solo e manejo adequado para as regiões tropicais. Campinas-SP : Embrapa Monitoramento por Satélite, 2010.

ROSOLEN, V.; HERPIN, U.; MELFI, A. J. Expansão dos solos hidromórficos na paisagem do sudoeste da bacia amazônica brasileira: mudanças texturais e de porosidade do solo. Caminhos de Geografia, Uberlândia, v. 7, n.20, p. 69-78, fev. 2007. Disponível em:

<http://www.seer.ufu.br/index.php/caminhosdegeografia/article/view/15478/8761>. Acesso em: 03 jun. 2012.

SCHAEFER, C. E. R; KER, J.C; GILKES, R. J.; CAMPOS, J.C.; COSTA, L. M.; SAADI, A. . Pedogenesis on the uplands of the Diamantina Plateau, Minas Gerais, Brazil: a chemical and micropedological study. Geoderma, v. 107, p. 243-269, jun. 2002. Disponível em: 〈http://www.sciencedirect.com/science/journal/00167061/107/3-4>. Acesso: 12 dez. 2010. 
SANTOS, R. D., LEMOS, R. C.; SANTOS, H. G.; KER, J. C.; ANJOS, L. H.C. Manual de descrições e coleta de solo no campo. 5 ed. Viçosa: Sociedade Brasileira de Ciência do Solo, 2005. 100p.

SAUER, D; SPONAGEL, H; SOMMER, M.; GIANI, L. JAHN, R.; STAHR, K. Review article podzol: soil of the year 2007 - a review on its Genesis, occurrence and functions. Journal of Plant Nutrition and Soil Science, v. 170, p. 581-597, outubro de 2007. Disponível em:

<http://onlinelibrary.wiley.com/doi/10.1002/jpln.200700135/abstract >. Acesso em 03/02/2012.

SOARES, B. F. Dinâmica dos elementos químicos e os processos de gênese e evolução dos solos de uma vertente do Planalto de Diamantina - Parque Estadual do Biribiri, Diamantina/MG. 2013, 188f. Dissertação (Mestrado em Geografia), Programa de Pós Graduação em Geografia - Tratamento da Informação Espacial, Pontifícia Universidade Católica de Minas Gerais, Belo Horizonte, 27 de setembro de 2013.

TARDY, Y. Pétrologie des Latérites et des Sols Tropicaux. Paris: Masson, 1993. p. 439-451.

VIDAL-TORRADO, P.; LEPSCH, I. F.; CASTRO, S. S.; COOPER, M. Pedogênese em uma sequência latossolopodzólico na borda de um platô na Depressão Periférica Paulista. Revista Brasileira de Ciências do solo, Viçosa, v.23, n.3, p. 909-921, 1999. Disponível em: <http://www.scielo.br/scielo.php?script=sci issues\&pid=01000683\&lng=pt\&nrm=iso>. Acesso em: 27 mar. 2013.

VIEIRA, L. S. Manual da Ciência do Solo com ênfase aos solos tropicais. São Paulo: Editora Agronômica Ceres, 1988. p. $293-310$.

VIZIER, J. F. Étude des phénomènes d'hydromorfie dans les sols des régions tropicales a saisons constrastées. Dynamique du fer et différenciation des profils. 1983. 294f. Tese (Doutorado) - ORSTOM, Paris.

WALKEY, A.; BLACK, I. A. An examination of the Degtjareff method for determining soil organic matter and a proposed modification of the cromic acids titration method. Soil Science, v. 37, p. 29-38, 1934.

\section{Agradecimentos}

Ao CNPq e FAPEMIG pela concessão de bolsas de estudos, à FAPESP pelo financiamento do projeto "Diferenciação das paisagens cársticas sobre rochas siliciclásticas na Serra do Espinhaço Meridional Brasil" (Processo 08/50157-5), coordenado pela professora Dra. Nádia Regina do Nascimento e ao Instituto Estadual de Florestas (IEF) e gestores do Parque Estadual do Biribiri por todo auxílio durante os trabalhos de campos realizados nesta pesquisa. 